\title{
ВОСТОЧНАЯ АНАЛИТИКА
}

Выпуск 3, 2020

\section{EASTERN ANALYTICS}

Issue 3, 2020 
Russian Academy of Sciences

Institute of Oriental Studies

\section{EASTERN ANALYTICS}

Issue 3, 2020

Moscow

2020 
Российская Академия наук

Институт востоковедения

\section{ВОСТОЧНАЯ АНАЛИТИКА}

Выпуск 3, 2020

Москва

2020 


\section{ISSN 2227-5568}

\section{Редакция}

В. В. Наумкин

(главныци редактор)

В. Я. Белокреницкий

(зам. главного редактора)

А. В. Акимов

Н. Ю. Ульченко

И. В. Федулов

\section{Члены редкоммегии}

А. К. Аликберов

А. Д. Васильев

А. В. Воронцов

А. Д. Воскресенский

А. С. Железняков

И. Д. Звягельская

В. А. Исаев

В. А. Кузнецов

C. Г. Лузянин

Н. М. Мамедова

Д. В. Мосяков

С. А. Панарин

Д. В. Стрельцов

Т. Л. Шаумян

Ответственный редактор выпуска - А. В. Акимов

Редактор статей на русском языке - Е. Ф. Щепилова

DOI: 10.31696/2227-5568-2020-03

(С) ФГБУН ИВ РАН, 2020 


\section{СОДЕРЖАНИЕ}

\section{ЭКОНОМИКА}

Авдаков И. Ю.

ТРАНСПОРТ ЯПОНИИ В СОВРЕМЕННОМ МИРЕ

Акимов А. В.

МОРСКОЙ ТРАНСПОРТ АЗИИ: КРАТКИЙ СТАТИСТИЧЕСКИЙ ОЧЕРК 15

Бизяев А. И.

РЕГУЛИРОВАНИЕ ОБЩЕСТВЕННОГО ТРАНСПОРТА В ИЗРАИЛЕ 28

Борисов М. Г.

ПЕРСПЕКТИВЫ ЭЛЕКТРИФИКАЦИИ АВТОМОБИЛЬНОГО ТРАНСПОРТА

В АЗИАТСКИХ СТРАНАХ.

Борисова Е. А.

ДОРОГИ ЦЕНТРАЛЬНОЙ АЗИИ. НОВЫЕ ПРОЕКТЫ

МЕЖДУНАРОДНОГО ТРАНЗИТА

Грайворонский В. В.

ТРАНСПОРТ МОНГОЛИИ 61

Маркарьян С. Б.

ЯПОНИЯ: ЕСТЬ ЛИ ШАНС ПОДНЯТЬ КОНКУРЕНТОСПОСОБНОСТЬ

СЕЛЬСКОГО ХОЗЯЙСТВА? (АНАЛИЗИРУЯ СТАТИСТИКУ)

Марьясис Д. А.

БАНКОВСКАЯ СИСТЕМА ИЗРАИЛЯ: СОВРЕМЕННОЕ СОСТОЯНИЕ

И ПЕРСПЕКТИВЫ РАЗВИТИЯ

Осипова М. $Г$.

МОРСКОЙ ТРАНСПОРТ РЕСПУБЛИКИ СИНГАПУР 
Растянникова Е. В.

МИРОВОЙ РЫНОК РЕСУРСОВ ЦВЕТНОЙ МЕТАЛЛУРГИИ

Томберг И. Г.

ТРУБОПРОВОДНАЯ ИНФРАСТРУКТУРА В ЭНЕРГЕТИЧЕСКОЙ ПОЛИТИКЕ КИТАЯ И ИНТЕРЕСЫ РОССИИ

Семенова Н. К.,Аристова Л. Б.

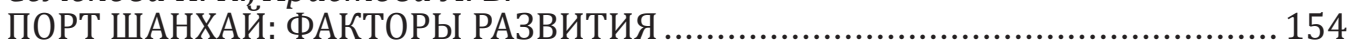

Чеснокова С. В.

ТРАНСПОРТ ИНДОНЕЗИИ ................................................................ 179

\section{ПОЛИТИКА}

Митрофаненкова О. Е.

МАРШРУТЫ АФГАНСКОГО НАРКОТРАФИКА

(КОНЕЦ ХХ В. - НАЧАЛО ХХІ в.)

Сарабьев А. В.

ПУЛ-ФАКТОРЫ ТРУДОВОЙ МИГРАЦИИ

ИЗ АРАБСКОГО МИРА В СТРАНЫ ЕВРОПЫ

Федорова И. Е.

К ИРАНО-ИНДИЙСКИМ ОТНОШЕНИЯМ 
Осипова М. Г.*

\title{
МОРСКОЙ ТРАНСПОРТ РЕСПУБЛИКИ СИНГАПУР
}

\author{
Osipova Maria**
}

MARITIME TRANSPORT OF SINGAPORE

DOI: 10.31696/2227-5568-2020-03-101-108

\begin{abstract}
Аннотация: В статье последовательно анализируется развитие морского транспорта Сингапура, начиная с колониальных времен и до наших дней. Особое внимание уделяется не только тенденциям современного развития морского порта Сингапура, но вопросам его будущей модернизации и структурной перестройки в ближайшие десятилетия.

Морской транспорт островного государства обладает мощным научно-техническим потенциалом и продолжает выполнять посреднические функции, обеспечивая работу шести свободных экономических зон, расположенных в морском порту.

Дальнейшее развитие и модернизация сингапурского порта будет происходить в соответствии с новейшими инновационными технологическими разработками и под строгим государственным контролем.
\end{abstract}

Ключевые слова: морской транспорт, порт, свободные экономические зоны, государственный контроль, посреднические функции, инновационные технологические разработки.

Abstract: The article analyzes the development of Singapore's Maritime transport from colonial times to the present day. Special attention is paid not only to the current trends in the development of the Singapore seaport, but also to the issues of its future modernization and structural adjustment in the coming decades.

Maritime transport of the island state has a strong scientific and technical potential and continues to perform intermediary functions, ensuring the operation of six free economic zones located in the seaport. Further development and modernization of the port of Singapore will take place in accordance with the latest innovative technological developments and under strict state control.

Keywords: maritime transport, Singapore seaport, future modernization, structural adjustment, intermediary functions, free economic zone, innovative technological development.

«Сингапур, как складочное место между Европой, Азией, Австралией и островами Индийского океана не заглохнет никогда » ${ }^{[1]}$

Морской порт Сингапура отличается удобным расположением в закрытом Малаккском проливе, что защищает его от бурь и штормов. Сингапур находится в стратегически важном районе земного шара (на стыке Азиатского и Австралийского материков, Тихого и Индийского океанов) и известен как один из самых удобных портов в мире. Начиная с 1819 г., статус «свободного»

\footnotetext{
"Осипова Мария Григорьевна - к.э.н., научный сотрудник центра Юго-Восточной Азии, Австралии и Океании ИВ PAH; e-mail: ossimarina @yandex.ru. ORCID: 0000-0003-2369-9558.

** Osipova Maria - PhD (Economics), senior research, Scientific Researcher Center of Southeast Asia, Australia and Oceania, IOS RAS; e-mail: ossimarina @yandex.ru. ORCID: 0000-0003-2369-9558.
} 
порта усиливал его географическое преимущество и способствовал успешному выполнению функций торгового посредника между метрополией и британскими колониями в Юго-Восточной Азии и на Дальнем Востоке. Это, в свою очередь, содействовало развитию в стране морского транспорта.

По мере увеличения объема морской торговли в первой четверти XIX века, Сингапур стал ключевым портом для парусных судов, следующих по азиатским морским путям. Иван Гончаров в «Фрегате Паллада» так отзывался о посреднической деятельности колонии: «(...) Сингапур,-писал он,- один из всемирных рынков, куда пока еще стекается все, что нужно и ненужно, что полезно и вредно человеку. Здесь есть необходимые ткани и хлеб, отрава и целебные травы. Немцы, французы, англичане, американцы, армяне, персияне, индусы, китайцы - все приехало продать и купить, других потребностей и целей нет» [2].

С 1840-х порт превратился в важный узел угольных перевалочных станций для сетей паровозных перевозок. В 1863 году И. А. Гончаров увидел сингапурский порт как суматоху, шум вокруг, как целую флотилию лодок. «...Запасные пакгаузы заперты тяжелыми дверьми, за которыми хранятся грузы, ожидающие кораблей, для развоза в Европу, в Китай, или Австралию. Они стоят безмолвные теперь. Но чуть завеет флаг, эти двери изрыгнут миллионы или поглотят их. Тут же выстроены обширные угольные сараи» [3]. Так продолжалось до 1869 г., до открытия в Египте Суэцкого канала. Он сразу изменил маршруты перевозок товаров по всему свету. Прежде корабли плыли из Европы через Дальний Восток, огибая Мыс Доброй Надежды. Открытие судоходства через Суэцкий канал изменило и сократило торговый путь на 50 миль, что увеличило объём торговли на 50\%. Сингапур, в результате этого географического открытия сделался ключевым центром Юго-Восточной Азии, первым портом захода кораблей, прибывающих с запада, в Юго-Восточную Азию. Если приходил корабль из Лондона и привозил товары, то было выгодно зайти в главный порт и, разделив груз на более мелкие партии, направить его в различные районы ЮВА. В этом заключалась посредническая концепция центров реэкспортной торговли. Экономическая деятельность колонии основывалась на посреднической торговле, а посредническая деятельность осуществлялась через морской порт Сингапура.

По мере того, как регион становился богаче, Сингапур вел торговлю со все большим числом стран, происходило оживление торгового судоходства в Малаккском проливе. Пришедшие на смену парусникам пароходы, сумели справиться с расширением мировой торговли, что способствовало быстрому экономическому процветанию британской колонии.

В октябре 1961 г., через два года после получения Сингапуром статуса самоуправления, началось строительство промышленного комплекса «Джуронг» и его собственного морского порта. Через три года была образована Морская Портовая Администрация Сингапура (Maritime and Port Authority of Singapore), еще через четыре года - Союз портовых офицеров. 
В 1971 г. произошла ликвидация военно-морской базы Великобритании и началось строительство новых причалов и мощностей порта. С этой целью, под строгим государственным контролем Морской Портовой Администрации (MPA), привлекались иностранные и местные частные инвестиции, формировался союз поставщиков различных услуг - судовых брокеров, морских страхователей, специалистов в области морского права, арбитража и финансирования и т.д.

Сингапурская модель развития имеет свои особенности, связанные с выгодным географическим положением и практически полным отсутствием природных ресурсов. То, что Сингапур находится на пересечении морских торговых путей оказалось чрезвычайно важным для развития морской отрасли в стране. Но это было лишь предпосылкой для успешного развития морского порта. Самым главным фактором расширения и модернизации порта явилась стратегия экономического развития, отправной точкой которой было создание привлекательных и удобных условий для усовершенствования работы морского транспорта. Расширение спектра морской торговли помогало в 60-70-е гг. проведению индустриализации в стране, затем осуществлению в 80-е гг. «второй промышленной революции» и, наконец, переходу страны к инновационному этапу экономики в 90-х гг.

Морской транспорт является краеугольным камнем деятельности свободных экономических зон в стране, доходы от которой направляются на экономическое развитие Республики Сингапур.

Из девяти сингапурских свободных экономических зон, шесть расположены на территории морского порта: «Брани Терминал», «Пассир Паньджанг Терминал», «Причалы Сембаванк», «Таньджунг Пагар Терминал», «Кеппел Терминал», «Джуронг Порт»[4].

Наиболее крупной промышленной зоной является «Джуронг» («Jurong»), где на территории в 56,8 кв. км расположено 1834 предприятия с числом занятых 100 тыс. человек. Преобладающая часть предприятий принадлежит иностранным инвесторам, остальные организованы в форме совместных предприятий. Важнейшими преимуществами зоны «Джуронг» является близость морского промышленного порта, военно-морской базы и хорошо развитые инфраструктурные системы.

Расширение спектра морских услуг способствовало повышению привлекательности порта как перевалочного центра в Азиатско-Тихоокеанском регионе. К 1972 г. в порту был принят и разгружен первый контейнеровоз. К 1981 контейнерные перевозки увеличились до 1 млн TEU, к 1990 г.-до 5 млн TEU и порт Сингапура вышел на первое место в мире по этому показателю. В 2019 г. объем контейнерных перевозок достиг показателя 37,2 млн TEU. (см. табл.№ 1). Около 85\% контейнеров, прибывающих в Сингапур, перегружаются на другие суда и следуют дальше.

Морская портовая администрация Сингапура (МРА) является подразделением министерства транспорта и определяет стандарты функционирования 
порта, стратегию его развития, правила морских служб и судоходства, проводит тендеры, привлекает зарубежных инвесторов. Деятельность морского порта строго контролируется государством. В условиях возрастающей конкуренции со стороны других крупных мировых портов МРА делает ставку на расширение порта и введение все новых дополнительных услуг, внедрение новейших инновационных технологий. Со многими странами были заключены соглашения о свободной торговле. Повышению привлекательности порта способствует внутренняя и внешняя политика Сингапура, направленная на преимущественное развитие морского транспорта.

В настоящее время порт Сингапура принимает суда из 123 стран мира. Порт обслуживают два оператора: PSA International Pte Ltd и Jurong Pte Ltd. Администрация порта Сингапура (PSA) является крупной транснациональной портовой корпорацией и контролирует около 3/4 грузооборота, имеет свою собственность и ведет бизнес во многих странах Азии. Глобальная портовая сеть Сингапура отличается особой предпринимательской тактикой, не подавляет конкурентов, а старается налаживать с ними сотрудничество. Морской порт делится на несколько кластеров: Танджонг Пагар, Кеппел и Брани на юге, Пасир Панджанг, Джуронг и остров Джуронг на юго-западе, Сембаванг на севере. Порт Джуронг - единственный из портовых районов Сингапура, принадлежит не портовой администрации Сингапура, а отдельной структуре Джуронг Таун Корпорейшн и подчиняется промышленной зоне Джуронг. Он оборудован большим количеством причалов, как мелких, так и больших, способных обслуживать около 250 линий и ежедневно принимать до 150 крупных судов (не считая мелкие и средние), обрабатывать около 80000 контейнеров. Причалы в Сембаванге построены на месте бывшей британской военной базы, ликвидированной только в 1971 г. и специализируются на обработке лесоматериалов, каучука и насыпных грузов.

Крупнейшие сингапурские нефтеперерабатывающие заводы имеют свои отдельные нефтеналивные причалы. На острове Себарок расположен терминал по хранению нефтепродуктов компании Сингапур Петролеум. Военно-морскому флоту Сингапура принадлежат причалы базы в Чанги, открытой в 2004 г. (эта база заменила старую военно-морскую базу на острове Брани, открытую в 1974 г.). Военно-морская база используется для базирования национальных военно-морских сил, а также ВМС Великобритании и кораблей 7-го флота США, может обеспечивать базирование кораблей всех классов до авианосцев включительно.

Статистика порта Сингапур

Таблий 1

\begin{tabular}{|c|c|c|c|c|c|}
\hline Год & $\begin{array}{c}\text { Тоннаж } \\
\text { прибытия судов } \\
\text { (млрд.GT) }\end{array}$ & $\begin{array}{c}\text { Контейнеро- } \\
\text { оборот } \\
\text { (млн ТEUs) }\end{array}$ & $\begin{array}{c}\text { Грузооборот } \\
\text { (млн тонн) }\end{array}$ & $\begin{array}{c}\text { Оунемерных } \\
\text { продаж } \\
\text { (млн тонн) }\end{array}$ & $\begin{array}{c}\text { в судовом рестре } \\
\text { Сингапура } \\
\text { (млн GT) }\end{array}$ \\
\hline 2014 & 2,37 & 33,9 & 581,3 & 42,4 & 82,2 \\
\hline
\end{tabular}




\begin{tabular}{|c|c|c|c|c|c|}
\hline Год & $\begin{array}{c}\text { Тоннаж } \\
\text { прибытия судов } \\
\text { (млрд.GT) }\end{array}$ & $\begin{array}{c}\text { Контейнеро- } \\
\text { оборот } \\
\text { (млн TEUs) }\end{array}$ & $\begin{array}{c}\text { Орузообомот } \\
\text { (млн тонн) }\end{array}$ & $\begin{array}{c}\text { Тоннаж } \\
\text { бункерных } \\
\text { продаж } \\
\text { (млн тонн) }\end{array}$ & $\begin{array}{c}\text { в судовом реестре } \\
\text { Сингапура } \\
\text { (млн GT) }\end{array}$ \\
\hline 2015 & 2,50 & 30,9 & 576,8 & 45,2 & 86,3 \\
\hline 2016 & 2,66 & 30,9 & 593,3 & 48,6 & 88,0 \\
\hline 2018 & 2,79 & 36,6 & 630,0 & 49,8 & 90,9 \\
\hline 2019 & 3,01 & 37,2 & 626,2 & 50,1 & 93,1 \\
\hline
\end{tabular}

Источник: 2020 Maritime and Port Authority of Singapore. URL: http://www.mpa.gov.sg.

Порт Сингапура - крупнейший порт мира не только по величине тоннаже судов, но и по грузообороту. Так, по итогам 2019 г., его грузооборот, хотя незначительно снизился по сравнению с 2018 г., но составил 626,2 млн т. Морской порт является ключевым фактором развития экономики страны. В морской отрасли занято более 180 тыс. человек. В настоящее время в Сингапуре работает более 150 международных судоходных групп, специализирующихся на различных сегментах рынка морских перевозок. По данным на конец 2019 г. более 5000 организаций в сфере морского судоходства обеспечивают около 7\% ВВП Сингапура. В сингапурском морском порту ежедневно швартуется почти 1000 кораблей и на них грузится примерно 0,5 млн тонн грузов. При таких объемах погрузочно-разгрузочных работ их организация должна находиться под самым пристальным надзором сотрудников центра управления портом. Ежедневно здесь разгружается примерно 80 тыс. контейнеров. Перевозят такие контейнеры корабли длина которых достигает 400 метров. Рассмотрим заход одного гигантского судна - 260-метрового корабля IPL Denver. Корабль ждет разрешения на вход примерно в одном километре от причала. Перед тем, как он войдет в порт, диспетчер должен понять, где находится судно. Для этого в порту установлены 11 радаров, которые следят за перемещениями нескольких тысяч судов, помимо этого по всему прилегающему побережью установлено более тысячи камер для наблюдения за кораблями. Вся информация поступает в высокотехнологичный центр управления порта. Инновационных технологий недостаточно для безопасной работы порта, необходимо осуществление контроля сотрудниками центра управления. Как только корабль входит в порт, навигационный модуль присваивает ему идентификационный номер, каждый тип корабля обозначается специальным символом. Корабли, груженные более чем 100000 тонн, входят в порт в сопровождении специальных катеров, которыми управляют диспетчеры центра управления. Трудно развернуть для захода в гавань такой корабль, как IPL Denver, массой 55 тыс.тонн, ведь порт находится в узком проливе. Недостаточно получить разрешение на вход в порт, нужно учитывать всякие непредвиденные обстоятельства. Например, при развороте большого корабля, траектория поворота может пересечься с выходящим из порта другим судном. Диспетчер на катере вступает в переговоры с капитаном 
корабля. Нужно пропустить выходящий из гавани корабль. 260-метровому кораблю приходится немного подождать, чтобы пришвартоваться. Огромные подъемные краны начинают разгружать контейнер, содержащий 500 тыс. тонн грузов, а диспетчер на катере отправляется встречать другой корабль[5].

Контейнерные терминалы расположены на окраинах центральной части Сингапура. В соответствии с государственным планом развития, принятом в 2012 г., все контейнерные операции были перемещены и сосредоточены в районе Туаса, на западной оконечности Сингапура. Целью этого проекта явилось построение высокотехнологичного порта, который повысит эффективность и производительность портовых операций, оптимизирует землепользование, улучшит безопасность, надежность и четкость работы морского порта. Строительство новых возможностей портового хозяйства только начинается и его планируется завершить к 2040-м годам. В результате порт Туас станет крупнейшим в мире контейнерным терминалом, сосредоточенным в одном месте. Контейнерный порт Туас активно использует цифровые технологии и искусственный интеллект для повышения эффективности работы терминала. Автоматизированные операции на причалах, грузовых районах позволяют операторам терминалов из диспетчерской дистанционно контролировать загрузку и выгрузку контейнеров с судов и на площадках складирования контейнеров. С помощью компьютеров, интеллектуальных датчиков и камер, операторы осуществляют наблюдение за работой нескольких причальных кранов-перегружателей и контейнерных погрузчиков одновременно.

Кроме того, по мере дальнейшей модернизации, порт Туас будет оснащен интеллектуальными портовыми системами, включая систему управления движением судов следующего поколения.

Морская Портовая Администрация Сингапура (МРА) реализует четыре проекта намыва искусственной территории, необходимой для развития порта Туас. К началу 2020 г. уже было выполнено дноуглубление и расширение подходных каналов, судоходных путей, акватории и причалов для захода более крупных контейнеровозов. В октябре 2019 г., для повышения эффективности работы порта и создания порта новейшего поколения, был запущен единый портал «digitalPORT@SGTM» для прохождения процедур очистки в порту. Такая платформа упрощает процедуру проверки соответствия судовым, иммиграционным и портовым санитарным требованиям от нескольких организаций в одном приложении, объединив 16 отдельных форм. Капитаны и судовые агенты из более чем 550 судоходных компаний теперь могут отправлять, отслеживать и получать разрешение на прибытие и отправление судов через данный портал[6].

На следующем этапе «digitalPORT@SGTM» оптимизирует ресурсы порта и повысит эффективность его работы с помощью искусственного интеллекта путем упрощения операций для оптимального планирования прохода судов в порту Сингапура. Такая платформа будет единым цифровым окном для 
бронирования морских услуг, она рассматривается МРА как продвижение единой системы обмена и стандартизации сетей (OCEANS). Цель создания такой системы беспрепятственное подключение между портами, обмен информацией и эффективные транзакции по всей морской транспортной цепочке.

МРА поощряет использование экологически чистого топлива, для снижения вредного воздействия судоходства на окружающую среду. Для расширения ассортимента судового топлива, поставляемого судам, заходящим в порт, начиная с 2017 г. разрабатывается сингапурская экосистема и инфраструктура для СПГ бункеровок. В мире только 117 судов используют сжиженный природный газ в виде топлива, две трети этих судов находятся в Европе. Развитие рынка бункеровки, то есть заправки морских и речных судов сжиженным природным газом, столкнулось с серьезными трудностями. Несмотря на жесткие ограничения экологического законодательства в отношении выбросов, судовладельцы предпочитают использовать экологические сорта традиционных топлив на уже существующих судах, нежели строить новый флот, ходящий на СПГ.

В Сингапуре МРА, совместно с правительственными учреждениями и предприятиями, было разработано Техническое руководство по СПГ бункеровкам (TR56), которым будут руководствоваться операторы при выполнении всех операций по СПГ бункеровкам в порту Сингапура. На международном уровне МРА сотрудничает с Администрациями Портов и Морскими Управлениями других стран в вопросах разработки набора согласованных стандартов и процедур СПГ бункеровки для океанских судов, заходящих в разные порты для заправки газовым топливом. Существуют иные виды экологического судового топлива, например биотопливо, электричество и топливо на основе водорода/аммиака, которые помогут снизить выбросы парниковых газов к 2030 и 2050 годам.

Туас Мегапорт станет единственным портом в Сингапуре после закрытия городских терминалов PSA в 2027 г. и терминала Пасир Панджанг в 2040 г., что положит конец эпохе морских транспортных перевозок в районе города[7].

Морской порт Сингапура имеет несколько паромных и круизных терминалов, которые связывают остров Сингапур с соседними странами и с другими островами страны. Республика Сингапур состоит из острова Сингапур и 63 близлежащих островков.

Круизный порт Сингапура включает в себя два терминала: Marina Bay Cruise Centre и Singapore Cruise Center. Новый круизный центр Marina Bay Cruise Centre был открыт в 2012 г. и является одним из самых крупных в Азии. Большие лайнеры пришвартовываются у нового терминала Marina Bay Cruise Centre, старый круизный терминал Singapore Cruise Center принимает средние и маленькие пароходы. Большинство туристических кораблей и паромов из Индонезии приплывает к причалам этого круизного центра. Центра обслуживают несколько пирсов. Паромный терминал Harbor Front 
Ferry Terminal, терминалы Tanah Merah Ferry Terminal и Pasir Panjang Ferry Terminal осуществляют перевозки на острова Индонезии.

Морской транспорт Сингапура является важной составляющей частью экономической стратегии страны. Островное государство, обладающее мощной научно-технической базой инновационных технологий, продолжает выполнять посреднические функции в мировой торговле, благодаря функционированию морского порта. Деятельность свободных экономических зон (две трети которых находятся на территории порта) обеспечивает бюджет страны необходимыми финансовыми ресурсами. Финансирование инновационной деятельности, техническая модернизация и расширение портового хозяйства осуществляются под строгим государственным контролем. С самого начала своего независимого развития государственный сектор в Сингапуре рассматривался как инструмент экономической стратегии, ее структурной перестройки. Такой инструмент экономической стратегии оказался весьма эффективным для расширения и модернизации и самой отрасли морского транспорта в стране. Строительство нового порта Туас к 2027 году выведет портовые операции из мегаполиса на новую, искусственно созданную, территорию. Целью проекта является создание интеллектуального порта следующего поколения, который повысит эффективность и производительность портовых операций. Отрасль морского транспорта Республики Сингапур в ближайшие десятилетия будет развиваться в соответствии с новыми мировыми информационными достижениями и явится важнейшим фактором успешного развития экономики острова.

\section{^итература/References}

1. Гончаров И. Фрегат Паллада. М.,1951 С. 272.

2. Там же. С. 279.

3. Там же. С. 283.

4. Осипова М. Г. Сингапур экономическая история. М., 2019. С. 29.

5. Особые экономические зоны (зарубежный и отечественный опыт). Книга вторая. М., 2017. C. 105.

6. Наука техника и мир. Организация морского порта Сингапура. Документальный фильм.

7. Port News. 01.08.2020. Интервью исполнительного директора морской и портовой администрации Сингапура Куа Лей Хун. 